\title{
Clinical characteristics of patients undergoing coronary artery bypass surgery: Focus on gender differences
}

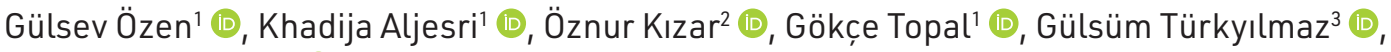 \\ Saygın Türkyılmaz ${ }^{3}$ (1) \\ 'Istanbul University, Faculty of Pharmacy, Department of Pharmacology, Istanbul, Turkey \\ ${ }^{2}$ Istanbul University, Faculty of Pharmacy, Istanbul, Turkey \\ ${ }^{3}$ Bakirkoy Dr Sadi Konuk Education and Research Hospital, Department of Cardiovascular Surgery, Istanbul, Turkey
}

ORCID IDs of the authors: G.Ö 0000-0002-8862-383X; K.A. 0000-0002-8527-5438; Ö.K. 0000-0002-4903-3677;

G.T. 0000-0001-7196-3179; G.T. 0000-0001-6910-7664; S.T. 0000-0003-2165-6853

Cite this article as: Ozen, G., Aljesri, K., Kizar, O., Topal, G., Turkyilmaz G., \& Turkyilmaz, S. (2020). Clinical characteristics of patients undergoing coronary artery bypass surgery: Focus on gender differences. Istanbul Journal of Pharmacy, 50 (3), 153-159.

\begin{abstract}
Background and Aims: The aim of the present study is to investigate whether the clinical characteristics of patients undergoing coronary artery bypass surgery (CAGB) differ by sex.

Methods: This study was performed with a total of 58 patients who underwent CABG. The age, weight, height, systolic and diastolic blood pressure, HbA1c, high-density lipoprotein (HDL), low-density lipoprotein (LDL) and total cholesterol values together with the demographic characteristics of patients undergoing CABG were collected and compared between male and female patients.

Results: In the present study, $71 \%$ of patients undergoing CABG were men and $29 \%$ of them were women. There was no significant difference in weight, systolic and diastolic blood pressure, $\mathrm{HbA1C}$, and total cholesterol values between male and female patients. Body mass index, LDL and HDL levels, the ratios of LDL/total cholesterol and HDL/total cholesterol were higher while height was lower in females compared to male patients.

Conclusion: Our study highlights the need for sex-specific approaches in the prevention of coronary artery diseases. Risk factors including obesity, diabetes, hypertension, and dyslipidemia influence the outcome of death in patients undergoing CABG. Correct management of controllable risk factors with the focus on gender differences could be beneficial in reducing mortality and morbidity rates by altering the prognosis of coronary artery diseases.
\end{abstract}

Keywords: Coronary artery bypass surgery, patient characteristics, gender differences, cardiovascular risk factors

\section{INTRODUCTION}

Cardiovascular diseases are the most common cause of death globally and are the major contributor to the burden of premature mortality and morbidity. According to the $\mathrm{WHO}$, cardiovascular diseases are responsible for approximately 17.9 million deaths every year (World Health Organization, 2017, https://www.who.int/health-topics/cardiovascular-diseases/\#tab=tab_1). More than 75\% of these deaths occur in low or middle income countries (Roth et al., 2017).

Among cardiovascular diseases, coronary artery disease (CAD), occurs primarily as a result of atherosclerosis of coronary arteries where plaque builds up inside them. Generally, patients with CAD are clasified into two types according to their symptoms 
(Cowell, Newby, \& Boon, 2004; Quertermous \& Ingelsson, 2016). The first type is patients with chronic stable angina characterized by myocardial ischemia, which develops as a result of an imbalance between the oxygen demand of myocardium and the oxygen supply, and is often accompanied by chest pain (Kabakçı et al.,1990). The second type is acute coronary syndrome which is also known as acute myocardial infarction (MI) and unstable angina (Cowell et al., 2004), where a plaque rupture, plaque erosion and coronary thrombosis may develop and sudden coronary death may occur (Otsuka et al., 2015). The severity of CAD and treatment options are determined by the type and number of coronary arteries where stenosis occurs. Pharmacological therapy in the treatment of CAD is applied in order to reduce myocardial oxygen demand and increase myocardial blood flow to the heart. This treatment is carried out with various agents including nitrates, beta-blockers, angiotensin converting enzyme inhibitors, antiplatelets, and anticoagulation agents (Willerson \& Helmes, 2015). Coronary revascularization is another frequently preferred safe and effective treatment method that improves myocardial perfusion and relieves myocardial ischemia symptoms (Wilson, 2015). Percutaneous coronary intervention (PCI) or coronary angioplasty is a widely used invasive treatment (Madhavan, Gersh \& Alexander, 2018). In severe cases where patients are not responding to other pharmacological treatment methods, a coronary artery bypass graft operation (CABG) represents a superior surgical intervention for myocardial revascularization (Samak et al., 2016).

CABG is an important surgical procedure that improves blood flow to the heart by using venous or arterial grafts to bypass the part of the coronary artery where occlusion due to atherosclerosis occurs (Jannati, Navaei, \& Ronizi, 2019). The CABG is known to be one of the most common surgical procedures worldwide with approximately 400,000 CABGs performed annually in the United States (Alexander \& Smith, 2016). The success of a CABG depends on the long-term patency of venous or arterial grafts (Goldman et al., 2004). However, surgical trends have decreased as the use of alternative options such as medical treatment and PCI have increased (Bachar \& Manna, 2020).

Hypertension, dyslipidemia, diabetes, kidney dysfunction, age, gender, lifestyle, cigarette smoking, diet, obesity, and family history have been found to be common risk factors for CAD in patients. Controlling these risk factors through lifestyle changes and, when necessary, through medical treatment can help to prevent CAD (Madhavan et al., 2018; Shao, Wang \& Tian, 2020). Development of CAD in women when they are younger occurs less than in men because of the protective effects of oestrogen. A long-term follow up study indicated that high levels of total cholesterol and low-density lipoprotein (LDL), as well as diabetes eliminate the female advantage (Koch, Khandwala \& Nussmeier, 2003; Bonow, Smaha \& Smith2002; Kannel \& Wilson, 1995). Furthermore, in the post-menopausal period, the same frequency of CAD was detected for both genders (Ahmad et al., 2010).

Several studies have indicated that female gender is an independent predictor of poor post-operative outcome after CABG and this could be due to differences in clinical characteristics between female and male patients (Nicolini et al., 2016; Em- mert et al., 2010; Bukkapatnam, Yeo \& Li , 2010). In the present study, age, weight, height, systolic and diastolic blood pressure, HbA1c (glycated haemoglobin), high-density lipoprotein $(\mathrm{HDL}), \mathrm{LDL}$, and total cholesterol values together with the demographic characteristics of patients undergoing CABG were collected and compared between male and female patients.

\section{MATERIALS AND METHODS}

\section{Subjects}

This study was performed with a total of 58 patients who underwent CABG in Bakirkoy Dr Sadi Konuk Education and Research Hospital between November 2018 and August 2019. Personal information and the pre-operative worksheet were used to obtain patients' clinical characteristics. Subjects in all age groups who underwent CABG surgery were included in the study. Exclusion criteria were as follows: Previous cardiac surgery (open), aortic and mitral disease, concomitant procedures (e.g., aortic annulus enlargement, ascending aorta replacement, more than single-valve surgery) and tricuspid annuloplasty. Patient's gender, age, weight, height, systolic and diastolic blood pressure, HbA1c, HDL, LDL and total cholesterol values together with their demographic characteristics were collected and recorded. The study was approved by the Institutional Review Board of Istanbul University, Institute of Cardiology (no: i.Ü.E.50.0.05.00/8). Patients enrolled in this study gave informed consent for all investigations.

\section{Statistical analysis}

The patients' age, weight, height, systolic and diastolic blood pressure, $\mathrm{HbA1c}, \mathrm{HDL}$, LDL and total cholesterol values were expressed in terms of their mean \pm standard error of mean (SEM). Body mass index (BMI) was calculated by dividing weight in kg by height in meter squared. Statistical analysis was performed using the Student's t-test. P value $<0.05$ indicated that data is significantly different. The statistical analysis was performed by using Graph Pad (Prism 7) software.

\section{RESULTS AND DISCUSSION}

Increased rates of in-hospital morbidity after CABG were observed in women (Koch et al., 2003). Furthermore, a meta analysis study including 966,492 patients reported that women had an increased risk for short-term, mid-term and long-term mortality compared with men undergoing CABG (Alam et al., 2013). This could be due to an unfavorable preoperative risk profile in women. In order to investigate this hypothesis, in the present study we compared several risk factors for CAD between women and men undergoing CABG in Turkey.

In the present study, $71 \%$ of the patients undergoing CABG were men and $29 \%$ of them were women. In accordance with our results, several studies indicated that the majority of patients who had undergone CABG were males (Ahmad et al., 2010; Koch et al., 2003; Varma et al., 2014; Elbardissi et al., 2012; Seccareccia et al., 2006; Dinh et al., 2008; McNeely, Markwell, \& Vassileva, 2016). Our study demonstrated that the mean age

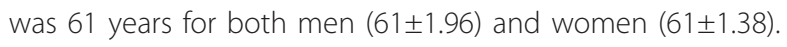
The age distribution of both genders is presented in Figure 1. The majority (47\%) of women were between $60-70$ years-old 
A

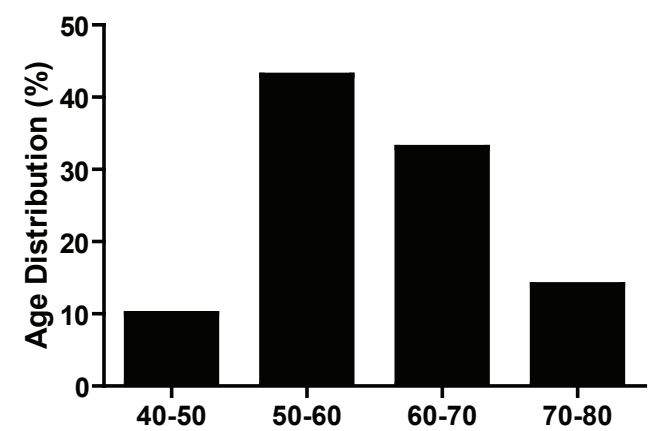

B

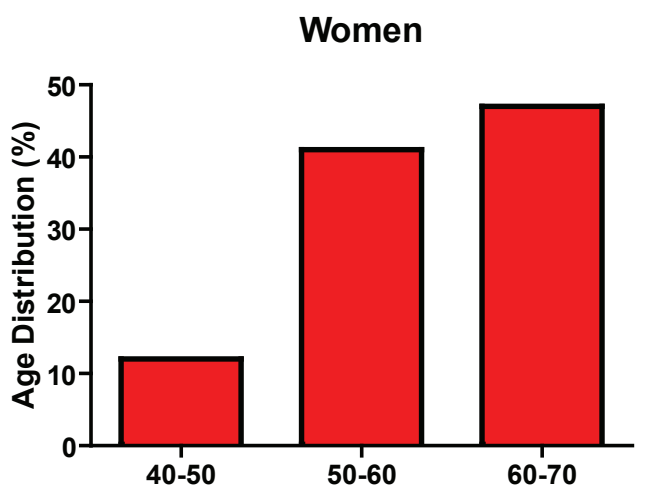

Figure 1. Age distribution of patients who underwent coronary artery bypass surgery. Age distribution is presented as percentage of number of patients (n value for men: 41, for women: 17).

while the majority of men (43\%) were between 50-60 yearsold. A different study performed on stable outpatients with suspected CAD demonstrated that mean age was 59 years for men and 62 years for women (Hemal et al., 2016). In accordance with that study, another study performed on patients undergoing CABG in Saudi Arabia demonstrated that women were significantly older than men (Ahmad et al., 2010). The discrepancy between these studies and our current results could be due to different ethnic groups included in these studies. In fact, Varma et al. compared the findings obtained from Indian and Western populations undergoing CABG (Varma et al., 2014). The mean age of Indian patients was 57 years while it was greater than 65 years in Western patients (Varma et al., 2014). This result is in accordance with the high risk profile of CAD in Asian-Indians (Ajay \& Prabhakaran, 2010). Furthermore, a recent study investigated the ages of patients undergoing
CABG from 1997 to 2011 in the United States and reported an increase in the mean of patient age with time (Cornwell, Omer \& Rosengart, 2015). Also, another study demonstrated an increase in mean age among US patients undergoing CABG from 2000 to 2009 (Elbardissi et al., 2012). These studies emphasized that ethnic groups and also the year when the studies were conducted could affect the results.

Obesity is an important risk factor for the development of CAD (Ades \& Savage, 2017). Furthermore, obesity is found to be a significant independent predictor for adverse outcomes and prolonged hospitalization after CABG (Prabhakar et al., 2002; Terada et al., 2016). BMI values are frequently used for the estimation of obesity degree. In the present study, the average height of women was significantly lower than men while there was no difference in weight between both genders (Figure 2).
A

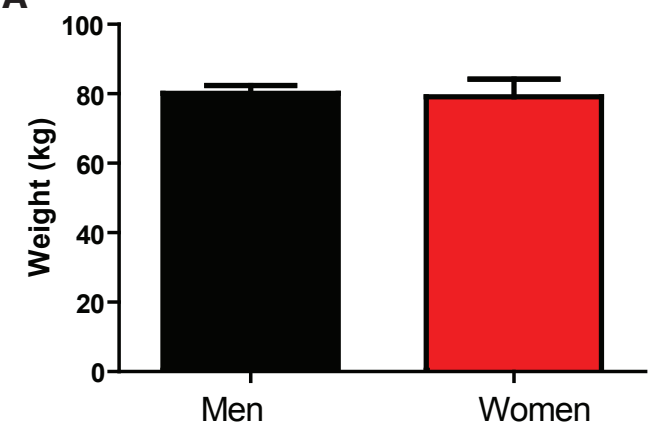

B

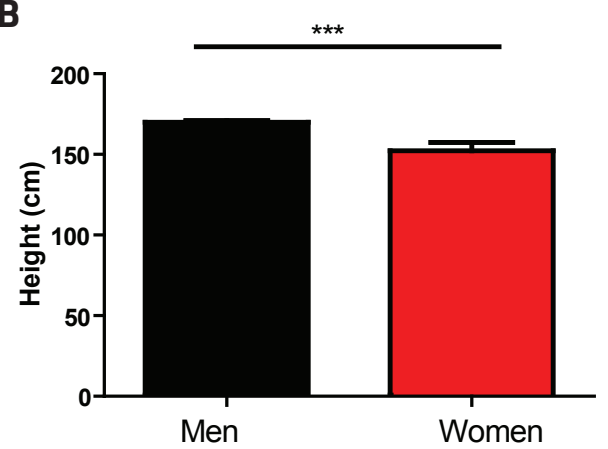

C

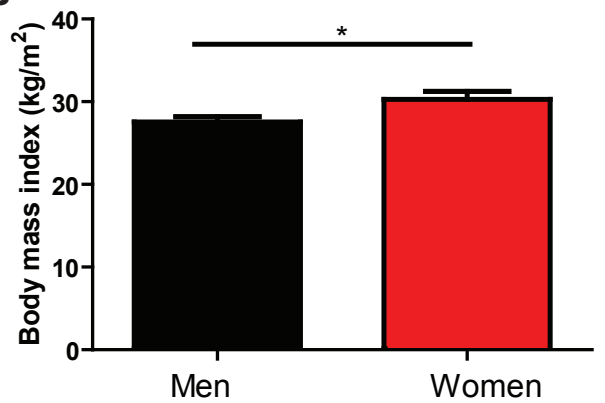

Figure 2. Weight, height and body mass index values of patients who underwent coronary artery bypass surgery. Body mass index is calculated by dividing weight in $\mathrm{kg}$ by height in meter squared. Values are means \pm s.e.mean derived from ( $\mathrm{n}$ ) different patients ( $\mathrm{n}$ value for women: 17 , for men: 41$).{ }^{*}$ indicates values significantly different $p<0.05,{ }^{* * *}$ indicates $p<0.001$ (student's $t$ test). 
A

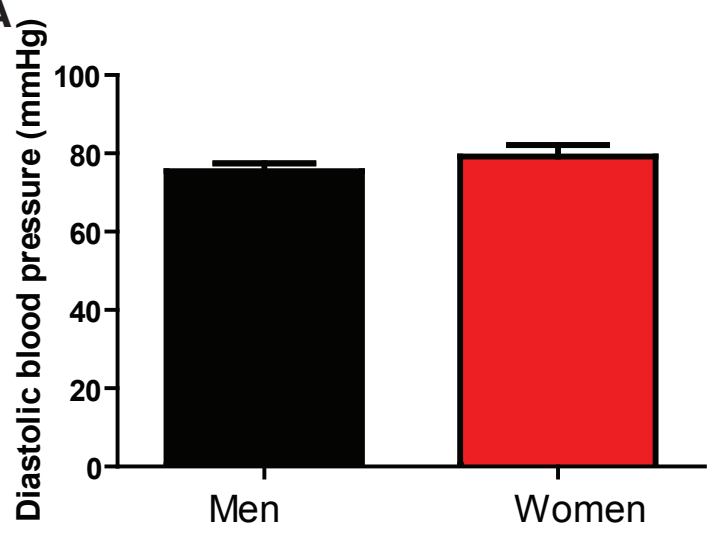

B

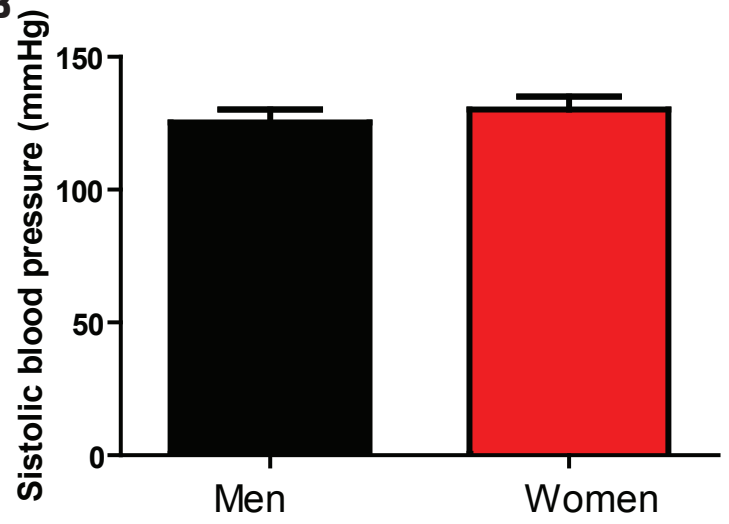

Figure 3. Diastolic and systolic blood pressure values of patients who underwent coronary artery bypass surgery. Values are means \pm s.e.mean derived from ( $\mathrm{n}$ ) different patients ( $\mathrm{n}$ value for women: 17, for men: 41).

Furthermore, BMI values were significantly higher in women (Figure 2). In accordance with our results, another study indicated that the prevalence of morbid obesity is higher in those women undergoing CABG than men (Ahmad et al., 2010). On the other hand, another study performed on patients undergoing CABG demonstrated that women were shorter, weighed less and had a lower BMI compared to men (Koch et al., 2003; Terada et al., 2016).

It is important to note that diet and exercise lifestyle modifications could have a potentially significant role in improving cardiovascular risk factors in patients who undergo CABG. Several gender differences were noted in diet and sedentary life habits. Men are more likely than women to exercise multiple times with higher intensity levels while women are more likely to adhere to long-term dietary advice. Moreover, exercise could have more beneficial effects on women than men in regards to quality of life and functional outcomes. Further studies are necessary in order to elucidate reasons for these differences between gender (Coyan, Reeder, \& Vacek, 2014; Markou, Evers \& van Swieten, 2008).

Hypertension is associated with an increase in cardiovascular morbidity of CABG patients during the perioperative period (Aronson, Boisvert, \& Lapp, 2002). Hypertension stage 1 is defined as sistolic/diastolic blood pressure equal to 130/80 mmHg or above (Whelton et al., 2018). In our study, we indicated no difference in sistolic and diastolic blood pressure between men and women (Figure 3). However, several studies reported that women with CAD were more likely to be hypertensive than men (Hemal et al., 2016; Ahmad et al., 2010).

The Framingham Heart Study reported that the presence of diabetes doubled the age-adjusted risk for CAD in men and tripled it in women (Kannel \& McGee, 1979). The HbA1c value is used for long-term glycemic control in diabetic patients and correlates best with mean blood glucose over the previous 8 to 12 weeks (Rohlfing et al., 2002). In our study, no differences in $\mathrm{HbA1c}$ values between men and women undergoing CABG were observed (Figure 4). In accordance with our results, the prevalence of diabetes in both women and men was similar (Hemal et al., 2016). However, in another

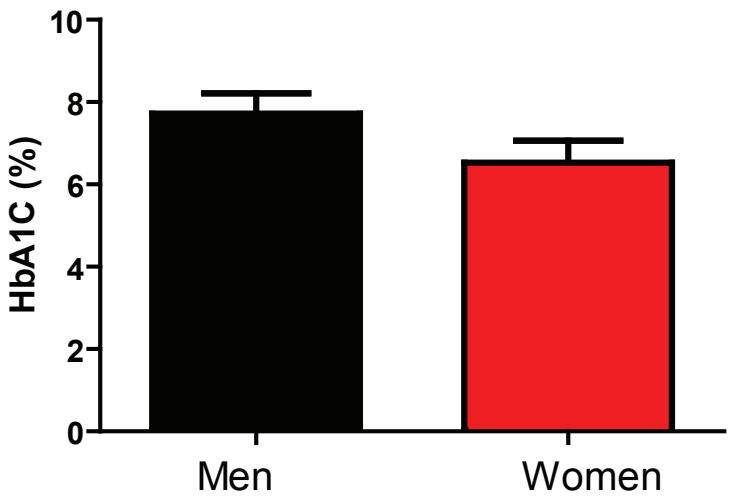

Figure 4. $\mathrm{HbA} 1 \mathrm{C}$ values of patients who underwent coronary artery bypass surgery. The term $\mathrm{HbA} 1 \mathrm{c}$ refers to glycated haemoglobin. Values are means \pm s.e.mean derived from $(n)$ different patients ( $n$ value for women: 17, for men: 41)

study, female patients had an increased incidence of diabetes mellitus (Ahmad et al., 2010).

The incidence of CAD in several studies was inversely related to $\mathrm{HDL}$ concentrations and positively related to LDL concentrations. The Framingham Heart Study indicated that the risk of Ml increases by $25 \%$ for every $5 \mathrm{mg} / \mathrm{dL}$ decrease in HDL levels for both men and women. On the other hand, lowering LDL levels is associated with a reduction in CAD (Castelli, 1983; Di Angelantonio et al., 2009; Praticò, Tangirala \& Rader, 1998; Ference et al., 2017) . In the present study, we indicated higher HDL and LDL levels in women compared to men (Figure 5). Furthermore, the ratios of HDL/total cholesterol and LDL/total cholesterol were greater in women than men (Figure 5). In accordance with our findings, another study indicated that women undergoing CABG had higher HDL, LDL and cholesterol values (Terada et al., 2016). Furthermore, several studies showed that female patients with CAD were more likely to have dyslipidemia than male patients (Ahmad et al., 2010). Higher LDL values observed in female patients could contribute to the progression of atherosclerotic CAD. In accordance with our results, a study performed in six countries reported that women have higher HDL values than men (Davis et al., 1996). 
A

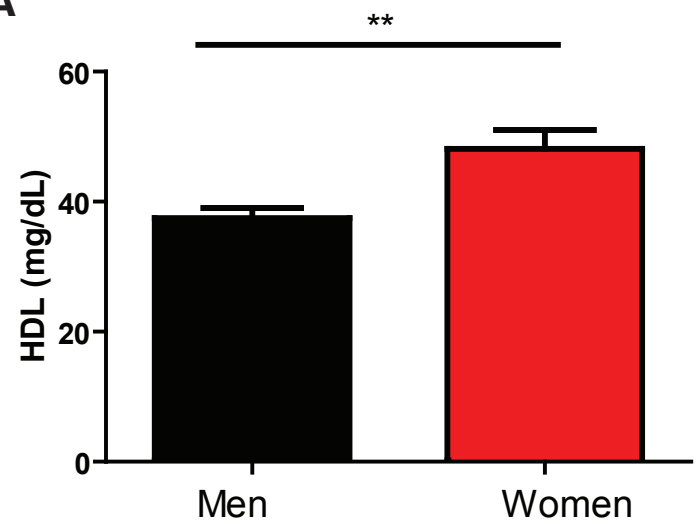

C

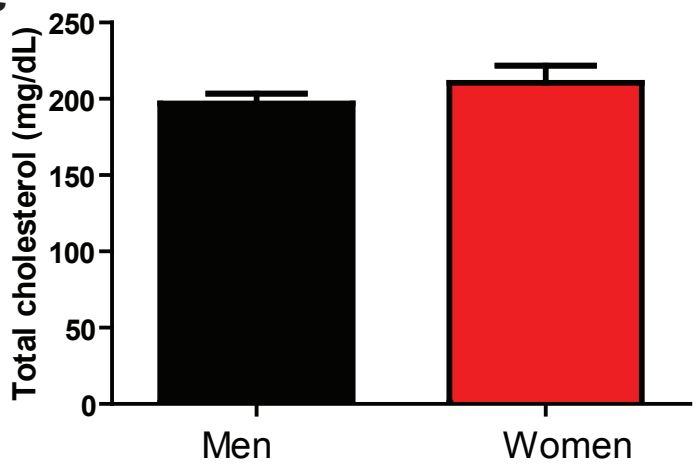

B

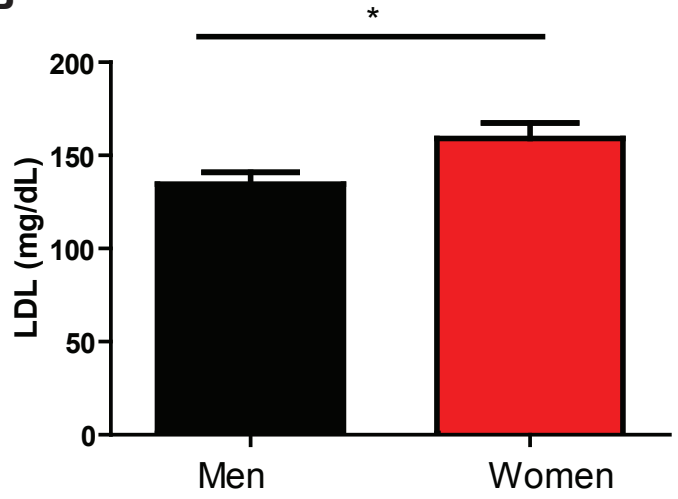

D

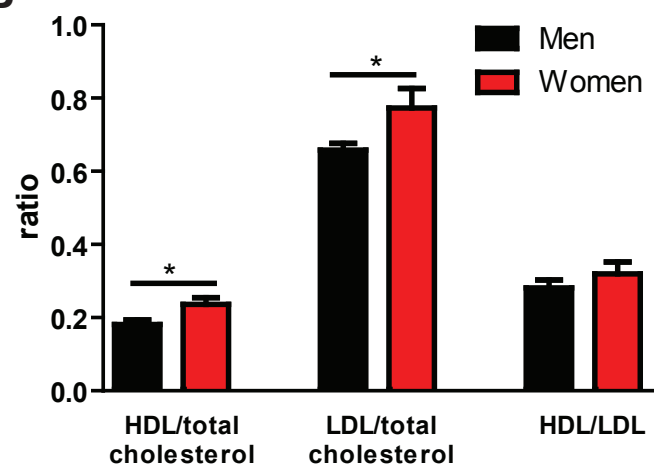

Figure 5. High-density lipoprotein (HDL), low-density lipoprotein (LDL), total cholesterol values and their ratios derived from patients who underwent coronary artery bypass surgery. Values are means \pm s.e.mean derived from ( $\mathrm{n}$ ) different patients ( $\mathrm{n}$ value for women: 17 , for men: 41 ). * indicates values significantly different $p<0.05$, ** indicates $p<0.01$ ( student's t test).

In conclusion, the present study reported a significant difference in lipid profile and BMl between women and men undergoing $C A B G$ and highlighted the need for sex-specific approaches for the prevention of CAD. Several studies investigated a gender difference in clinical characteristics of patients undergoing CABG. Our study has both consistent as well as opposing results with those previous studies. This could be due to genetic predisposition, differences in ethnic groups, access to healthcare for diagnosis, and awareness of patients for cardiovascular risk factors. Risk factors including obesity, diabetes, hypertension and dyslipidemia influence the outcome of death in patients undergoing CABG. Correct management of controllable risk factors significantly reduces mortality and morbidity rates by altering the prognosis of CAD and is important for reducing hospital costs of these patients. Therefore, major socioeconomic education and preventive measures are needed to reduce the burden of major co-morbidities in patients with CAD and to seek early cardiac advice and care. A relatively low number of patients were included in the present study and this is one limitation of the study. Further multicenter studies including higher numbers of Turkish patients undergoing $C A B G$ with the focus on gender differences are needed.

Ethics Committee Approval: This study was approved by the Institutional Review Board of the Istanbul University Institute of Cardiology (no: 50.0.05.00/8)
Informed Consent: Written consent was obtained from the participants.

Peer-review: Externally peer-reviewed.

Author Contributions: Conception/Design of Study- G.Ö., S.T., G.T., G.T.; Data Acquisition- G.Ö., K.A., Ö.K.; Data Analysis/Interpretation- G.Ö.; Drafting Manuscript- G.Ö., K.A.; Critical Revision of Manuscript- G.T., S.T. G.T.; Final Approval and Accountability- G.Ö., K.A., Ö.K., G.T., G.T., S.T.; Technical or Material Support- Ö.K.; Supervision- G.Ö.

Conflict of Interest: The authors have no conflict of interest to declare.

Financial Disclosure: This study was supported by Scientific Research Projects Coordination Unit of Istanbul University. (Project number:TSA2018-31849)

\section{REFERENCES}

- $\quad$ Ades, P. A., \& Savage, P. D. (2017). Obesity in coronary heart disease: An unaddressed behavioral risk factor. Preventive Medicine, 104, 117-119. https://doi.org/10.1016/j.ypmed.2017.04.013

- Ahmad, M., Arifi, A. A., Onselen, R. van, Alkodami, A. A., Zaibag, M., Khaldi, A. A. A., \& Najm, H. K. (2010). Gender differences in the surgical management and early clinical outcome of coronary artery disease: Single centre experience. Journal of the Saudi Heart Association, 22(2), 47-53. https://doi.org/10.1016/j. jsha.2010.02.004 
- $\quad$ Ajay, V. S., \& Prabhakaran, D. (2010). Coronary heart disease in Indians: Implications of the INTERHEART study. Indian Journal of Medical Research, 132(5), 561-566. https://doi.org/10.4103/09715916.73396

- $\quad$ Alam, M., Bandeali, S. J., Kayani, W. T., Ahmad, W., Shahzad, S. A., Jneid, H. ... Virani, S. S. (2013). Comparison by meta-analysis of mortality after isolated coronary artery bypass grafting in women versus men. American Journal of Cardiology, 112(3), 309-317. https://doi.org/10.1016/j.amjcard.2013.03.034

- $\quad$ Alexander, J. H., \& Smith, P. K. (2016). Coronary-artery bypass grafting. The New England Journal of Medicine, 375(10), 22-33. https:// doi.org/10.1056/NEJMc1608042

- $\quad$ Aronson, S., Boisvert, D., \& Lapp, W. (2002). Isolated systolic hypertension is associated with adverse outcomes from coronary artery bypass grafting surgery. Anesthesia and Analgesia, 94(5), 1079-1084. https://doi.org/10.1097/00000539-200205000-00005

- Bachar, B. J., \&Manna, B. (2020). Coronary artery bypass graft. statpearls. Retrieved from http://www.ncbi.nlm.nih.gov/pubmed/29939613

- Bonow, R. O., Smaha, L. A., Smith, S. C., Mensah, G. A., \& Lenfant, C. (2002). World Heart Day 2002: The international burden of cardiovascular disease: Responding to the emerging global epidemic. Circulation, 106(13), 1602-1605. https://doi.org/10.1161/01. CIR.0000035036.22612.2B

- Bukkapatnam, R. N., Yeo, K. K., Li, Z., \& Amsterdam, E. A. (2010). Operative Mortality in Women and Men Undergoing Coronary Artery Bypass Grafting (from the California Coronary Artery Bypass Grafting Outcomes Reporting Program). American Journal of Cardiology, 105(3), 339-342. https://doi.org/10.1016/j.amjcard.2009.09.035

- Castelli, W. P. (1983). Cardiovascular disease and multifactorial risk: Challenge of the 1980s. American Heart Journal, 106(5), 11911200. https://doi.org/10.1016/0002-8703(83)90174-6

- Cornwell, L. D., Omer, S., Rosengart, T., Holman, W. L., \& Bakaeen, F. G. (2015). Changes over time in risk profiles of patients who undergo coronary artery bypass graft surgery: The Veterans Affairs Surgical Quality Improvement Program (VASQIP). Journal of the American Medical Association (JAMA), 150(4), 308-315. https://doi. org/10.1001/jamasurg.2014.1700

- Cowell, S. J., Newby, D. E., \& Boon, N. A. (2004). Coronary artery disease in the elderly patient. Reviews in Clinical Gerontology, 14(2), 105-118..https://doi.org/10.1017/S095925980400139X

- Coyan, G. N., Reeder, K. M., \& Vacek, J. L. (2014). Diet and exercise interventions following coronary artery bypass graft surgery: A review and call to action. Physician and Sportsmedicine, 42(2), 119-129. https://doi.org/10.3810/psm.2014.05.2064

- Davis, C. E., Williams, D. H., Oganov, R. G., Tao, S. C., Rywik, S. L., Stein, Y., \& Little, J. A. (1996). Sex difference in high density lipoprotein cholesterol in six countries. American Journal of Epidemiology, 143(11), 1100-1106. https://doi.org/10.1093/oxfordjournals.aje. a008686

- Di Angelantonio, E., Sarwar, N., Perry, P., Kaptoge, S., Ray, K. K., Thompson, A., ... Danesh, J. (2009). Major lipids, apolipoproteins, and risk of vascular disease. Journal of the American Medical Association (JAMA), 302(18), 1993-2000. https://doi.org/10.1001/ jama.2009.1619

- Dinh, D. T., Lee, G. A., Billah, B., Smith, J. A., Shardey, G. C., \& Reid, C. M. (2008). Trends in coronary artery bypass graft surgery in Victoria, 2001- 2006: findings from the Australasian society of cardiac and thoracic surgeons' database project. The Medical Journal of Australia, 188, 214-217. https://doi.org/10.5694/j.1326-5377.2008.tb01587.x

- $\quad$ Elbardissi, A. W., Aranki, S. F., Sheng, S., O'Brien, S. M., Greenberg, C. C., \& Gammie, J. S. (2012). Trends in isolated coronary artery bypass grafting: An analysis of the Society of Thoracic Surgeons adult cardiac surgery database. Journal of Thoracic and Cardiovascular Surgery, 143(2), 273-281. https://doi.org/10.1016/j.jtcvs.2011.10.029
Emmert, M. Y., Salzberg, S. P., Seifert, B., Schurr, U. P., Odavic, D., Reuthebuch, O., \& Genoni, M. (2010). Despite modern off-pump coronary artery bypass grafting women fare worse than men 2$\}$. Interactive CardioVascular and Thoracic Surgery, 10(5), 737-741. https://doi.org/10.1510/icvts.2009.220277

Ference, B. A., Ginsberg, H. N., Graham, I., Ray, K. K., Packard, C. J., Bruckert, E. ...Catapano, A. L. (2017). Low-density lipoproteins cause atherosclerotic cardiovascular disease. 1. Evidence from genetic, epidemiologic, and clinical studies. A consensus statement from the European Atherosclerosis Society Consensus Panel. European Heart Journal, 38(32), 2459-2469. https://doi. org/10.1093/eurheartj/ehx144.

Goldman, S., Zadina, K., Moritz, T., Ovitt, T., Sethi, G., Copeland, J. G. ... Henderson, W. (2004). Long-term patency of saphenous vein and left internal mammary artery grafts after coronary artery bypass surgery: Results from a Department of Veterans Affairs Cooperative Study. Journal of the American College of Cardiology, 44(11), 2149-2156. https://doi.org/10.1016/j.jacc.2004.08.064

Hemal, K., Pagidipati, N. J., Coles, A., Dolor, R. J., Mark, D. B., Pellikka, P. A. ... Douglas, P. S. (2016). Sex differences in demographics, risk factors, presentation, and noninvasive testing in stable outpatients with suspected coronary artery disease insights from the PROMISE Trial. Journal of the American College of Cardiology (JACC):Cardiovascular Imaging, 9(4), 337-346. https://doi. org/10.1016/j.jcmg.2016.02.001

- Jannati, M., Navaei, M., \& Ronizi, L. (2019). A comparative review of the outcomes of using arterial versus venous conduits in coronary artery bypass graft (CABG). Journal of Family Medicine and Primary Care, 8(9), 2768. https://doi.org/10.4103/jfmpc. jfmpc_367_19

- Kabakçı, M. G., Oto, A., Oram, E., Karamhmetoğlu, A., Oram, A., \& Uğurlu, Ş. (1990). Dilitiazem Therapy in Stable Angina Petoris: A Placebo-Controlled Study. Turk Kardiyoloji Derneği Arsivi, 18(3), 170-175. Retrieved from: https://archivestsc.com/tr/jvi. aspx?pdir=tkd\&plng=tur\&un=TKDA-53458\&look4=

Kannel, W. B., \& McGee, D. L. (1979). Diabetes and cardiovascular risk factors: The Framingham study. Circulation, 59(1), 8-13. https://doi.org/10.1161/01.CIR.59.1.8

Koch, C. G., Khandwala, F., Nussmeier, N., \& Blackstone, E. H. (2003). Gender profiling in coronary artery bypass grafting. Journal of Thoracic and Cardiovascular Surgery, 126(6), 2044-2051. https:// doi.org/10.1016/S0022-5223(03)00955-3

- Madhavan, M. V., Gersh, B. J., Alexander, K. P., Granger, C. B., \& Stone, G. W. (2018). Coronary Artery Disease in Patients $\geq 80$ Years of Age. Journal of the American College of Cardiology, 71(18), 20152040. https://doi.org/10.1016/j.jacc.2017.12.068

- Markou, A. L. P., Evers, M., van Swieten, H. A., \& Noyez, L. (2008). Gender and physical activity one year after myocardial revascularization for stable angina. Interactive CardioVascular and Thoracic Surgery, 7(1), 96-101. https://doi.org/10.1510/icvts.2007.160382

- McNeely, C., Markwell, S., \& Vassileva, C. (2016). Trends in Patient Characteristics and Outcomes of Coronary Artery Bypass Grafting in the 2000 to 2012 Medicare Population. Annals of Thoracic Surgery, 102(1), 132-138. https://doi.org/10.1016/j.athoracsur.2016.01.016

- Nicolini, F., Vezzani, A., Fortuna, D., Contini, G. A., Pacini, D., Gabbieri, D., ... Gherli, T. (2016). Gender differences in outcomes following isolated coronary artery bypass grafting: Long-term results. Journal of Cardiothoracic Surgery, 11(1), 144-150. https:// doi.org/10.1186/s13019-016-0538-4

- Otsuka, F., Byrne, R. A., Yahagi, K., Mori, H., Ladich, E., Fowler, D. R. ... Joner, M. (2015). Neoatherosclerosis: Overview of histopathologic findings and implications for intravascular imaging assessment. European Heart Journal, 36(32), 2147-2159. 
- Prabhakar, G., Haan, C. K., Peterson, E. D., Coombs, L. P., Cruzzavala, J. L., \& Murray, G. F. (2002). The risks of moderate and extreme obesity for coronary artery bypass grafting outcomes: A study from the society of thoracic surgeons' database. Annals of Thoracic Surgery 74, 1125-1131 https://doi.org/10.1016/S00034975(02)03899-7

- Praticò, D., Tangirala, R. K., Rader, D. J., Rokach, J., \& FitzGerald, G. A. (1998). Vitamin E suppresses isoprostane generation in vivo and reduces atherosclerosis in ApoE-deficient mice. Nature Medicine, 4(10), 1189-1192. https://doi.org/10.1038/2685

- Quertermous, T., \& Ingelsson, E. (2016). Coronary Artery Disease and Its Risk Factors: Leveraging Shared Genetics to Discover Novel Biology. Circulation Research, 118(1), 14-16. https://doi. org/10.1161/CIRCRESAHA.115.307937

- Rohlfing, C. L., Wiedmeyer, H. M., Little, R. R., England, J. D., Tennill, A., \& Goldstein, D. E. (2002). Defining the relationship between plasma glucose and HbA1c: Analysis of glucose profiles and $\mathrm{HbA1c}$ in the Diabetes Control and Complications Trial. Diabetes Care, 25(2), 275-278. https://doi.org/10.2337/diacare.25.2.275

- Roth, G. A., Johnson, C., Abajobir, A., Abd-Allah, F., Abera, S. F., Abyu, G., ... Murray, C. (2017). Global, Regional, and National Burden of Cardiovascular Diseases for 10 Causes, 1990 to 2015. Journal of the American College of Cardiology, 70(1), 1-25. https:// doi.org/10.1016/j.jacc.2017.04.052

- Samak, M., Fatullayev, J., Sabashnikov, A., Zeriouh, M., Schmack, B., Ruhparwar, A., ... Weymann, A. (2016). Total Arterial Revascularization: Bypassing Antiquated Notions to Better Alternatives for Coronary Artery Disease. Medical Science Monitor Basic Research, 22, 107-114. https://doi.org/10.12659/MSMBR.901508

- Seccareccia, F., Perucci, C. A., D'Errigo, P., Arcà, M., Fusco, D., Rosato, S., \& Greco, D. (2006). The Italian CABG Outcome Study: Shortterm outcomes in patients with coronary artery bypass graft surgery. European Journal of Cardio-Thoracic Surgery, 29(1), 56-62. https://doi.org/10.1016/j.ejcts.2005.07.017

- Shao, C., Wang, J., Tian, J., \& Tang, Y. D. (2020). Coronary Artery Disease: From Mechanism to Clinical Practice. Advances in Experimental Medicine and Biology,1177, 1-36. https://doi.org/10.1007/978981-15-2517-9_1
Terada, T., Johnson, J. A., Norris, C., Padwal, R., Qiu, W., Sharma, A. M. ... Forhan, M. (2016). Severe obesity is associated with increased risk of early complications and extended length of stay following coronary artery bypass grafting surgery. Journal of the American Heart Association, 5(6), e003282. https://doi.org/10.1161/ JAHA.116.003282

Varma, P. K., Kundan, S., Ananthanarayanan, C., Panicker, V. T., Pillai, V. V., Sarma, P. S., \& Karunakaran, J. (2014). Demographic profile, clinical characteristics and outcomes of patients undergoing coronary artery bypass grafting - retrospective analysis of 4,024 patients. Indian Journal of Thoracic and Cardiovascular Surgery, 30(4), 272-277. https://doi.org/10.1007/s12055-014-0318-5

- Kannel, W. B. \& Wilson, P. W. F. (1995). Risk Factors That Attenuate the Female Coronary Disease Advantage. Archives of Internal Medicine, 155(1), 57-61. https://doi.org/10.1001/ archinte. 1995.00430010063008

- Whelton, P. K., Carey, R. M., Aronow, W. S., Casey, D. E., Collins, K. J., Dennison Himmelfarb, C. ... Wright, J. T. (2018). 2017 ACC/AHA/ AAPA/ABC/ACPM/AGS/APhA/ASH/ASPC/NMA/PCNA Guideline for the Prevention, Detection, Evaluation, and Management of High Blood Pressure in Adults: A Report of the American College of Cardiology/American Heart Association Task Force on Clinical Practice Guidelines. Circulation, 138(17), e484-e594. https://doi. org/10.1161/CIR.0000000000000596

World Health Organization. (2017, 17 May). Cardiovascular diseases. [Web log post]. Retrieved from: https://www.who.int/healthtopics/cardiovascular-diseases/\#tab=tab_1

- Willerson, J. T., \& Holmes D. R. (2015). Coronary artery disease. Switzerland, AG: Springer Nature.

- Wilson, J. M. (2015). Coronary Artery bypass surgery and percutaneous coronary revascularization: Impact on morbidity and mortality in patients with coronary artery disease. London, UK: Springer. 